\title{
Editorial
}

\section{The Interdisciplinary Chronic Kidney Disease Clinic: End of the Beginning, Not Beginning of the End}

\author{
Jerry Yee ${ }^{a}$ Ruth C. Campbell ${ }^{b}$ \\ ${ }^{a}$ Nephrology and Hypertension, Henry Ford Hospital, Detroit, MI, and ${ }^{\mathrm{b}}$ Medical University of \\ South Carolina, Charleston, SC, USA
}

In this issue of the American Journal of Nephrology, Nee et al. [1] demonstrate that patients who initiated dialysis while receiving care through the Military Health System (MHS) had a superior 1-year survival than those who initiated dialysis outside of the MHS. MHS patients were also more likely to receive pre-end-stage renal disease (ESRD) nephrology care (defined as nephrology care, dietary education, and use of erythropoiesis-stimulating agents [ESAs]) and have a functioning arteriovenous fistula (AVF) at the commencement of dialysis compared to non-MHS patients. AVF placement and preESRD nephrology care provided much of the survival advantage. Pre-ESRD nephrology care of greater than 12 months' duration had a survival impact comparable to that of a functioning AVF. The authors concluded that pre-ESRD nephrology care and vascular access placement led to less mortality.

The results derived from these data in some ways are not surprising. Dialysis initiation with an AVF has long been associated with decreased mortality for incident hemodialysis patients, and access placement has been a defining goal of pre-ESRD nephrology care. The interesting twist is that pre-ESRD nephrology care itself, not just the

\section{KARGER}

(c) 2017 S. Karger AG, Basel

E-Mail karger@karger.com

www.karger.com/ajn
AVF placement, was also associated with the mortality benefit. This finding adds to the recent studies by Quinn et al. [2] and Brown et al. [3] that propose a more nuanced view of the optimal care of patients with chronic kidney disease (CKD) stages 4 and 5. In these studies, patients who underwent an ultimately non-successful AVF placement and initiated dialysis with a hemodialysis catheter had improved mortality compared to those who had initiated dialysis with a catheter and had yet not undergone AVF construction. These findings imply that it is not solely the vascular access itself but also the prosecution of pre-ESRD nephrology care for greater than 12 months that provides an equal portion of the survival advantage following the onset of dialysis.

The results of Quinn et al. [2] and Brown et al. [3] augment and complement the growing body of literature that demonstrates the benefits of pre-ESRD nephrology care, particularly in the form of an interdisciplinary CKD clinic. Pre-ESRD nephrology education using an interdisciplinary approach results in more patients beginning dialysis at home, and also leads to a greater percentage of patients with a permanent access when in-center hemodialysis is chosen [4]. The interdisciplinary CKD clinic 
offers important benefits beyond preparation for dialysis. It is associated with lower mortality for pre-ESRD patients [5] and has been shown to retard the progression of kidney disease [6] compared to usual primary care.

These results raise the question of whether AVF placement, although clearly important, should be the defining goal of pre-ESRD CKD care. They shift the focus of preESRD CKD care from a single aspect of care to a more multifactorial approach that encompasses the management of CKD progression and its complications; education regarding options for managing advanced CKD with dialysis, transplantation, or supportive care; dialysis modality; vascular access placement; and, ultimately, the transition to dialysis or conservative management. Interdisciplinary CKD care may also be a venue for providing conservative management of advanced CKD. However, significant, patient-related cognitive dysfunction may preclude sufficient pre-ESRD education [7].

While the inclusive mission of the interdisciplinary CKD clinic may fulfill the needs of many patients and nephrologists, it may also ignite a spark of anxiety. How does one define and quantify the quality of CKD care of this scope? This is a critical question for clinical research and for practicing nephrologists held accountable for their patients' clinical outcomes. AVF placement and its use for initiation of dialysis is a clean, binary outcome that is easy to measure and therefore accounts for one part of interdisciplinary CKD performance. "Nephrology care" and "interdisciplinary CKD care" are more amorphous concepts that raise questions such as "What exactly is/are the important part(s) of interdisciplinary CKD care?" And, "Are they replicable?" This holistic approach is readily apparent but difficult to quantify. Simply, it may be better to approximate clinical reality, particularly in this patient-centered care era. The progression of CKD is heterogeneous, and interventions may need to be modified based on patient characteristics and patient-related goals [4]. Quality measures will need to embrace patientcentered care.

Why is it that so many more patients in the MHS received pre-dialysis, interdisciplinary CKD care compared to non-MHS patients? One reason is the lack of a financial infrastructure to support interdisciplinary CKD clinics in the United States. The interdisciplinary kidney team is usually comprised of a nephrologist, advanced practice provider, and a nurse. The interdisciplinary CKD clinic composition is variable and contingent upon exigent needs of the local, medical environment. It may include a dietician, social worker, and/or pharmacist based on the requirements and resources of the practice. Some larger clinics may have infusion rooms for intravenous iron, kidney transplantation medications, or simple saline solutions. In a fee-based medical system, it may be difficult to support interdisciplinary CKD team members who cannot generate sufficient income or whose services are non-billable.

The progression of CKD may be a slow and unpredictable process for many patients [4]. Thus, it may take several years to demonstrate a financial benefit, particularly if a patient changes health care systems or insurance providers. A significant challenge for the interdisciplinary clinics of any type is to delineate the cost savings that it generates. In the past, many interdisciplinary CKD clinics focused on anemia management, which generated revenue to support the clinical staff. As hemoglobin targets are now lower and as ESA use has decreased, anemia management may no longer represent a sustainable business model for most private or academic practitioners, that is, a highly organized and effective, interdisciplinary CKD clinic is generally not a profitable venture. In some circumstances, an interdisciplinary CKD clinic may run at a financial loss. In a self-contained, protocolized, and mandated medical system such as the Veterans Association or MHS, it is likely easier to financially justify the interdisciplinary model because the entire cost of care is considered. Principally, the initial and recurring expenses of the CKD clinic are offset by the downstream savings that are realized when patients begin dialysis within the same system or are transitioned safely to conservative care, absent of multiple hospitalizations that were avoided by optimal outpatient CKD care. Essentially, such wellplanned systems are simply not relegated to a short-term profit center tactics, but, instead, a long-term cost-savings strategy. Not surprisingly, US dialysis providers are supporting interdisciplinary CKD clinics, following patients from pre-ESRD status to dialysis within their own spheres of influence. Better prepared patients who transition to ESRD are hospitalized less, thereby maintaining optimal hemodialysis chair occupancy and profitability.

A second advantage of self-contained health care systems like the MHS is a comprehensive medical record that is shared by all providers across inpatient and outpatient settings, as discussed by Nee and his collaborators. Despite the rapid adoption of electronic health records and adoption of "meaningful use," overall communication among electronic health record platforms remains poor. This suboptimal circumstance may produce communication lapses among providers, fragmented care after hospital discharge, difficulty in arranging referrals for specialty care such as vascular access surgery, and dietary 
education, leading to generalized failure to deliver timely, high-quality care.

We acknowledge that interdisciplinary CKD clinics work successfully. They are associated with slower progression of CKD, patients who are better prepared for renal replacement therapy, and improvements in mortality rates. The data from Nee and colleagues [1] should be used to help justify and develop effective care systems to deliver patient-centered care for those with advanced CKD. Nephrologists have the tools to significantly help patients with advanced $\mathrm{CKD}$, and we must determine the optimal way to use them. Echoing Churchill, the develop- ment of an interdisciplinary CKD clinic is "not even the beginning of the end" of our journey toward idealized CKD care, but perhaps, "the end of the beginning."

End Quotation

Now this is not the end. It is not even the beginning of the end. But it is, perhaps, the end of the beginning. - Winston Churchill (1942).

\section{Disclosure Statement}

The authors have no conflicts of interest to declare.

\section{References}

1 Nee R, Fisher E, Yuan CM, Agodoa LY, Abbott KC: Pre-end-stage renal disease care and early survival among incident dialysis patients in the US military health system. Am J Nephrol 2017;45:464-472.

2 Quinn RR, Oliver MJ, Devoe D, Poinen K, Kabani R, Kamar F, Mysore P, Lewin AM, Hiremath S, MacRae J, James MT, Miller L, Hemmelgarn BR, Moist LM, Garg AX, Chowdhury TT, Ravani P: The effect of predialysis fistula attempt on risk of all-cause and access-related death. J Am Soc Nephrol 2017;28:613-620.
3 Brown RS, Patibandla BK, Goldfarb-Rumyantzev AS: The survival benefit of "fistula first, catheter last" in hemodialysis is primarily due to patient factors. J Am Soc Nephrol 2017;28: 645-652.

4 Hazzan AD, Halinski C, Agoritsas S, Fishbane S, DeVita MV: Epidemiology and challenges to the management of advanced CKD. Adv Chronic Kidney Dis 2016;23:217-221.

5 Hemmelgarn BR, Manns BJ, Zhang J, Tonelli M, Klarenbach S, Walsh M, Culleton BF: Association between multidisciplinary care and survival for elderly patients with chronic kidney disease. J Am Soc Nephrol 2007;18:993999.
6 Peeters MJ, van Zuilen AD, van den Brand JA, Bots ML, van Buren M, Ten Dam MA, Kaasjager KA, Ligtenberg G, Sijpkens YW, Sluiter HE, van de Ven PJ, Vervoort G, Vleming LJ, Blankestijn PJ, Wetzels JF: Nurse practitioner care improves renal outcome in patients with CKD. J Am Soc Nephrol 2014;25:390-398.

7 Jasinski MJ, Lumley MA, Soman S, Yee J, Ketterer MW: Indicators of cognitive impairment from a medical record review: correlations with early (30-d) readmissions among hospitalized patients in a nephrology unit. Psychosomatics 2017;58:173-179. 